\title{
Ocorrência de Puccinia dichondrae - agente causal da ferrugem - em orelha-de-rato (Dichondra repens)
}

\author{
Rayane Louise Candida Diniz ${ }^{1}$, Alicionon de Oliveira Caetano ${ }^{1}$, Jennifer Decloquement ${ }^{2}$, Jakelinny \\ Martins Silva ${ }^{1}$, Milton Luiz da Paz-Lima ${ }^{1}$ \\ ${ }^{1}$ Instituto Federal Goiano, Câmpus Urutaí, Urutaí, Goiás, Brasil. E-mail: fitolima@gmail.com, rayanelouise@ yahoo.com.br, \\ sonoum.16@hotmail.com, jakelinny.1989@hotmail.com \\ ${ }^{2}$ Institut Universitaire de Technologie de Béthune, Béthune, France. E-mail: jennifer.decloquement@ laposte.net
}

Recebido: 13/06/2016; Aceito: 24/10/2016.

\section{RESUMO}

Orelha-de-rato (Dichondra repens - Convolvulaceae) é uma planta perene de baixo crescimento, considerada como forrageira. O trabalho teve como objetivo a identificação da ferrugem da orelha-de-rato causada por Puccinia sp. Amostras de folhas de orelha-de-rato foram coletadas no município de Bento Gonçalves, RS, exsicatadas e depositadas na coleção micológica de referência do IF Goiano Câmpus Urutaí e, posteriormente, analisadas em microscópio estereoscópico. Lâminas semi-permanentes e cortes histológicos foram realizados. Para registro dos sintomas e sinais do patógeno fez-se macro e microfotografias. A morfometria das estruturas reprodutivas foi realizada utilizando microscópio óptico. O fitopatógeno apresentou télia de coloração marrom avermelhado, hipófila e subepidérmica encontrada na face abaxial da folha, com dimensões 180-260 x 210-340 $\mu \mathrm{m}$. Teliósporos lisos, bicelulares, com dimensões de 32,1 - (27,1) - 22,2 x 19,4 - (14,8) - 11,3 $\mu$ m de coloração pardo a marrom avermelhado com papila de comprimento 7,5 - $(5,0)-2,6 \mu \mathrm{m}$, hialina e pedicelos filiformes e hialinos, com comprimento de 24,7 - (12,6) - 6,7 $\mu \mathrm{m}$. Inicialmente os teliósporos jovens apresentaram-se hialinos e quando maduros se tornaram melanizados. Com base nas características descritivas da fase telial o isolado oriundo de Bento Gonçalves, RS, (2011) foi identificado como Puccinia dichondrae.

Palavras-chave: etiologia, forrageira, identificação, teliósporos, télia.

\section{Occurence Puccinia dichondrae, causal agent of the rust kidney weed (Dichondra repens)}

\begin{abstract}
Dichondra or kidney weed (Dichondra repens - Convolvulaceae), is a perennial low growing plant, considered as forage and your center of origin is the Southeastern United States of America (USA). This study aimed to identify the kidney weed rust caused by Puccinia sp. Samples of mouse ear leaves, were collected in Brazilian city of Bento Gonçalves, RS, made herbarium specimens where were analyzed in stereoscopic microscope. Semipermanent slides and histological cuts, together with macro and microphotographs of pathogens symptoms and signs were performed. The morphology of the reproductive structures was performed using digital "Toup View", measurement system. The pathogen presented telia was reddish brown color, hipofila and subepidermal leaf surface, with dimensions 180-260 x 210-340 $\mu \mathrm{m}$. Teliospores was smooth, bicellular, with dimensions of 32,1-(27,1)-22,2 x 19,4-(14,8)-11,3 $\mu \mathrm{m}$, with color brown to reddish brown with papilate length 7.5-(5.0)-2,6 $\mu \mathrm{m}$, hyaline and pedicels filiform hyaline with length of 24,7-(12,6)-6,7 $\mu \mathrm{m}$. Initially young, presented hyaline teleospores and when ripe become melanized. Based on the descriptive characteristics of teleomorphic phase isolated native of Bento Gonçalves, RS, (2011) was identified as Puccinia dichondrae.
\end{abstract}

Key words: etiology, forage, identification, teliospore, telia. 


\section{Introdução}

A orelha-de-rato (Dichondra repens J.R.Forst. \& G.Forst. - Convolvulaceae) é uma forrageira popularmente conhecida como dinheiro-em-penca, corriola e corda-de-viola-rasteira, e trata-se de uma planta perene de baixo crescimento, nativa do sudeste dos Estados Unidos da América (EMMONS; ROSSI, 2015). É usada em parques e jardins substituindo o gramado com maestria, principalmente em locais semisombreados nas regiões de clima mais ameno. Não tolera o frio, geadas ou estiagem prolongada, é de baixa manutenção, exige duas fertilizações por ano e cortes mensais (SARROCCO et al., 2009).

A planta multiplica-se por sementes, rizomas ou pedaços de ramos. Em alguns casos pode tornar-se invasiva multiplicando-se de maneira espontânea em gramados convencionais onde é algumas vezes considerada como planta daninha. Sua ramagem é arroxeada e bastante ramificada. Comercialmente é oferecida em forma de placas e mantas vegetadas (LORENZI, 2001). As margens do limbo foliar são reniformes a oblongo-circulares, medindo de 5-25 mm de comprimento. Possui flores solitárias com pedicelo de 10-50 mm de comprimento, com os lóbulos do cálice no formato oblongo-elípticas, medindo de 2,5-4 $\mathrm{mm}$ de comprimento, de coloração pálida amarelo-esverdeada (LORENZI, 2001). É uma planta herbácea rasteira com forte enraizamento nos nós, de caules não ramificados e revestidos por pilosidade brancacenta, de 20-40 cm de comprimento (LORENZI, 2008; EMMONS; ROSSI, 2015).

A ferrugem da orelha-de-rato causada por Puccinia dichondrae Mont. foi identificada pela primeira vez no continente americano, no Chile em 1852 (MUJCA; VERGARA, 1945). No Brasil sua primeira ocorrência foi relatada por Hennen et al. (1982) e na África do Sul por Doidge (1948). O registro mais recente para Puccinia dichondrae foi descrito por Sarrocco et al. (2009) na Itália. De acordo com Farr e Rossman (2016) Puccinia dichondrae possui como sinonímias os seguintes nomes Dicaeoma dichondrae (Mont.) e Micropuccinia dichondrae (Mont.).

O fitopatógeno $P$. dichondrae pertence ao reino Fungi, filo Basidiomycota, sub-divisão Pucciniomycotina, classe Pucciniomycetes, ordem Pucciniales, família Pucciniaceae. É biotrófico e como todas as ferrugens não apresenta fase saprófita, sua sobrevivência ocorre graças a fase sexual (BEDENDO, 2011). De acordo com Cummins e Hiratsuka (1983) os fitopatógenos causadores de ferrugens podem apresentar ciclo de vida com cinco fases distintas sendo elas pícnia, écio, urédia, télia e basídia, cada uma dessas fases produz esporo diferente responsável pelo desenvolvimento e sobrevivência do patógeno.
De acordo com a descrição feita por Gay (1852) quando a hospedeira é infectada por Puccinia dichondrae, grandes quantidades de pústulas desenvolvem-se na face abaxial da folha, raramente ocorrem sobre a face adaxial e no pecíolo. Os urediniósporos são liberados após a maturação e são capazes de germinar e produzir ciclos secundários da doença. As pústulas se desenvolvem próximas umas às outras, tendo formato confluente, arredondado, convexo ou hemi-esféricas com tamanho próximo à cabeça de um alfinete. Apresentam coloração regularmente marrom, e acima da epiderme foliar, assim, quando liberam-se os urediniósporos, a pústula fica fragmentada. Os teliósporos são oblongos e de coloração amarronzada, são septados e apresentam um ápice obtuso hialino que varia de coloração preta a cinza. Segundo Cardin et al. (2005), P. dichondrae afeta as plantas de Dichondra repens deixando seus pecíolos eretos com folhas enroladas e dobradas ao longo da nervura central de modo a que a face abaxial fica totalmente exposta, enquanto plantas sadias ficam prostradas com superfícies foliares planas.

Este patógeno pode infectar a planta sob temperatura variável entre 16 e $24{ }^{\circ} \mathrm{C}$, sendo a temperatura de $18{ }^{\circ} \mathrm{C}$ e clima úmido as condições ótimas para seu desenvolvimento (CARDIN et al., 2005). Os teliósporos são transmitidos principalmente através do vento pois na superfície foliar apresentam-se em uma camada pulverulenta. Como as plantas se desenvolvem muito próximas uma das outras o fungo encontra facilidade para disseminar, através do contato físico. A água também é um método de disseminação, tanto a chuva quanto a irrigação podem favorecer a infestação, visto que para germinar a planta exige umidade por volta de $95 \%$; por este motivo existe maior disseminação e infecção em épocas de período chuvoso e frio (BEDENDO, 2011). No Brasil, Puccinia dichondrae infecta as seguintes hospedeiras: Dichondra repens J.R. Forst. \& G. Forst., D. sericea Sw. e Dichondra sp. J.R. Forst. \& G. Forst. De acordo com Farr e Rossman (2016) foram realizados 32 registros de ocorrência de Puccinia dichondrae no mundo listando como hospedeiras: Dichondra sp., $D$. brevifolia, $D$. carolinensis, D. micranta, D. repens, D. repens var. carolinensis e D. sericea. Há registros do fitopatógeno em aproximadamente 15 países diferentes, sendo eles: África do Sul, Argentina, Austrália, Bermudas, Brasil, Bolívia, Chile, Equador, EUA, França, Guatemala, Itália, Nova Zelândia, Quênia e Uruguai (FARR e ROSSMAN, 2016).

O presente trabalho tem como objetivo identificar, descrever a sintomatologia, etiologia, epidemiologia de Puccinia dichondrae ao infectar a planta orelha-de-rato (Dichondra repens). 


\section{Material e Métodos}

Amostras de folhas orelha-de-rato apresentando sintomas típicos de ferrugem foram coletadas no município de Bento Gonçalves - RS, no ano de 2011. Estas folhas foram exsicatadas e analisadas em microscópio estereoscópico. Utilizando pinça e estilete, propágulos do patógeno foram transferidos para lâminas contendo fixador lactofenol $\left(200 \mathrm{~mL} . \mathrm{L}^{-1}\right.$ fenol fundido, 200 mL.L ${ }^{-1}$ ácido lático; 400 mL.L -1 $^{-1}$ glicerina branca; 0,5 h.L $\mathrm{L}^{-1}$ azul de algodão; $200 \mathrm{~mL} . \mathrm{L}^{-1}$ água purificada). Com auxílio de lâmina de barbear foram realizados transversalmente cortes histológicos retirando fragmentos contendo sinais do patógeno, estes fragmentos foram transferidos para lâminas contendo fixador. As lâminas foram vedadas com esmalte para unhas.

Foram realizadas macrofotografias das amostras evidenciando os sintomas em ambas as faces das folhas, sendo que os sinais do patógeno foram encontrados apenas na face abaxial caracterizando esse tipo de ferrugem como hipófila. Sob microscópio de luz as lâminas foram visualizadas; télia e teliósporos tiveram suas características qualitativas descritas e tabuladas. Utilizando microscópio marca Nikon ${ }^{\circledR}$ modelo H550L conectado à câmara de captura digital acoplada ao software ToupView ${ }^{\circledR}$ mediu-se as dimensões de 100 télias (através do corte histológico); em relação aos teliósporos mediu-se o comprimento do pedicelo, profundidade da papila e dimensões. As medidas qualitativas (formato, cor) e quantitativas da fase telial foram tabeladas e comparadas de acordo com as informações descritas para táxons de espécies de fungos causadores de ferrugens descritas para orelha-de-rato por Saccardo (1888), Doidge (1948) e Saccardo et al. (2009).

Foram realizados registros dos sintomas das folhas infectadas e as microfotografias das estruturas fúngicas no microscópio óptico, utilizando câmera digital Canon ${ }^{\circledR}$ modelo Power Shot A580 para confecção da prancha de fotos. As fotos foram editadas com o software Microsoft Office Picture Manager ${ }^{\circledR}$ e a prancha foi organizada no Microsoft Office Power Point ${ }^{\circledR}$.

\section{Resultados e Discussão}

Analisando as características morfológicas e morfométricas descritas na Tabela 1 e comparando os valores encontrados para o isolado de Bento Gonçalves (2011) com as descrições em literatura dos autores Saccardo (1888), Doidge (1948) e Sarrocco et al. (2009), o patógeno foi identificado e caracterizado como sendo Puccinia dichondrae.

Tabela 1. Aspectos morfológicos e morfométricos do isolado de Puccinia dichondrae de Bento Gonçalves (2011) comparados às descrições de Saccardo (1888), Doidge (1948) e Sarrocco et al. (2009) registrados para orelha-de-rato.

\begin{tabular}{|c|c|c|c|c|c|}
\hline Estruturas reprodutivas & $\begin{array}{c}\text { Isolado Bento } \\
\text { Gonçalves, (2011) }\end{array}$ & $\begin{array}{c}\text { SACCARDO } \\
(\mathbf{1 8 8 8})\end{array}$ & DOIDGE (1948) & $\begin{array}{c}\text { SARROCCO et al. } \\
(2009)\end{array}$ & RESULTADO \\
\hline \multicolumn{6}{|l|}{ Télia: } \\
\hline Posição da pústula na folha & hipófila & hipófila & hipófila & hipófila, raro anfígena & Confirmado \\
\hline Dimensões $(\mu \mathrm{m})$ & $180-260 \times 210-340$ & $70-100$ & nd & $89,3-(115,8)-155,1$ & Não confirmado \\
\hline Coloração & Marrom avermelhado & nd & marrom & Marrom escuro & $\begin{array}{c}\text { Confirmado Doidge } \\
\text { (1948) e Sorrocco et al. } \\
\text { (2009) }\end{array}$ \\
\hline \multicolumn{6}{|l|}{ Teliósporo: } \\
\hline Número de células & bicelular & bicelular & bicelular & bicelular & Confirmado \\
\hline Forma & clavado & clavado & $\begin{array}{c}\text { oblongo, assimétrico, } \\
\text { clavado ou oblongo } \\
\text { clavado }\end{array}$ & nd & $\begin{array}{c}\text { Confirmado Saccardo } \\
\text { (1888) e Doidge (1948). }\end{array}$ \\
\hline Coloração & sub-hialino & nd & sub-hialino a hialino & Castanho amarelado & $\begin{array}{c}\text { Confirmado Doidge } \\
\text { (1948). }\end{array}$ \\
\hline Presença de septação mediana & Presente & $\begin{array}{l}\text { Presente e } \\
\text { constrito }\end{array}$ & presente e constrito & presente e constrito & Confirmado \\
\hline Dimensões $(\mu \mathrm{m})$ & $\begin{array}{c}32,1-(27,1)-22,2 \times 19,4- \\
(14,8)-11,3\end{array}$ & $30-40 \times 12-8$ & $25-45 \times 14-19$ & nd & $\begin{array}{c}\text { Confirmado Saccardo } \\
\text { (1888) e Doidge (1948). }\end{array}$ \\
\hline $\begin{array}{l}\text { Comprimento/ dimensão do } \\
\text { Pedicelo }(\mu \mathrm{m})\end{array}$ & $24,7-(12,6)-6,7$ & $20 \times 4$ & $25 \times 5$ & $7,05-(13,8)-23,5$ & Confirmado \\
\hline Profundidade da papila $(\mu \mathrm{m})$ & $7,5-(5,0)-2,6$ & nd & $1-6 \times 5-7,5$ & $9,4-18,8 \times 18,8-37,6$ & $\begin{array}{c}\text { Confirmado Doidge } \\
\text { (1948). }\end{array}$ \\
\hline Forma do ápice & cônino & nd & cônico & cônico & $\begin{array}{c}\text { Confirmado Doidge } \\
\text { (1948) e Sorrocco et al. } \\
\text { (2009) }\end{array}$ \\
\hline Hospedeiro descrito & D. repens & $\begin{array}{l}\text { D. repens e } D . \\
\text { sericeae }\end{array}$ & D. repens & D. repens & Confirmado \\
\hline Superfície & lisa & tênue a lisa & lisa & lisa & Confirmado \\
\hline
\end{tabular}


Em orelha-de-rato foram observados sintomas que se confundem com características de folhas jovens e maduras; pontos escuros de coloração marrom e protuberantes na face abaxial da folha denominados pústulas (Figura 1A).

$\mathrm{Na}$ amostra de $D$. repens oriunda de Bento Gonçalves (2011), foi encontrada a fase telial da ferrugem. A télia adquiriu uma coloração marrom escuro e em seguida rompe-se a epiderme por onde são liberados os teliósporos que ao serem expelidos acumulam-se ao redor da télia ou são disseminados pelo vento depositando-se sobre a superfície. As estruturas de esporulação são bem visíveis na face abaxial da folha, devido ao acúmulo de teliósporos ao redor da télia (Figura 1C). De acordo com a incidência da ferrugem, o tecido na face adaxial da folha apresentava coloração amarelada (sem a presença de sinais) (Figura 1B) (SARROCCO et al., 2009).

A amostra apresentou pústulas de coloração marrom avermelhada, subepidérmica, convexas, na posição hipófila, recobrindo quase toda a superfície da hospedeira, com a télia (Figura 1DEF) medindo 180260 x 210-340 $\mu \mathrm{m}$. O teliósporo apresentou-se como sendo bicelular (Figura 1H), clavado com septação mediana presente e constricta (Figura 1GH), com superfície lisa, coloração sub-hialina em teliósporos imaturos de coloração amarronzada em teliósporos maduros (Figura 1G), com dimensões de 32,1-22,2 x 19,4-11,3 $\mu \mathrm{m}$, apresentando pedicelo com comprimento de $24,7 \times 6,7 \mu \mathrm{m}$, papila cônica única mais comum e rara quando dupla (Figura 1I) com profundidade de 7,5 x 2,6 $\mu \mathrm{m}$ (Tabela 1).

Segundo a análise comparativa de caracteres morfológicos e morfométricos do isolado de Puccinia sp. de Bento Gonçalves em comparação ao isolado encontrado por Saccardo (1888) pôde-se confirmar que ambos os teliósporos apresentavam septação mediana, sendo bicelulares, clavados e com superfície variando de tênue a lisa. Em análise comparativa entre o isolado de Bento Gonçalves e Doidge (1948) os isolados apresentaram télia de coloração marrom a marrom avermelhado, possuindo teliósporos bicelulares, clavados, de coloração variando de sub-hialino a hialino, com septação mediana, com ápice cônico e superfície lisa. Comparando a descrição morfológica de Sarrocco et al. (2009) e o isolado de Bento Gonçalves (2011) este e aqueles apontaram télia de coloração marrom avermelhado a marrom escuro, com teliósporos bicelulares, com septação mediana, com ápice cônico e superfície lisa. Nas descrições morfológicas dos diversos autores o patógeno foi apontado ao infectar $D$. repens.
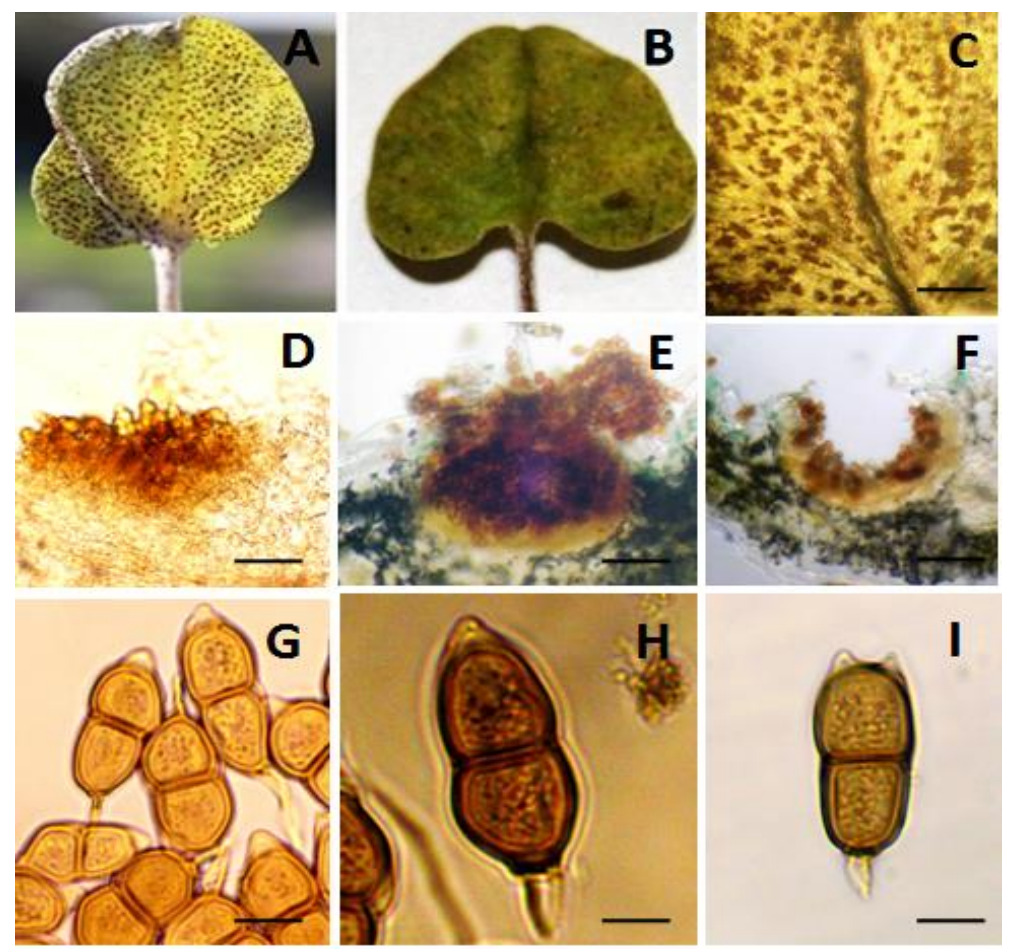

Figura 1. Ferrugem causada por Puccinia dichondrae incidente em folhas de orelha-de-rato (Dichondra repens). A. Sintoma na face abaxial, B. Sintomas amarelados na face adaxial, C. Detalhe das pústulas na face abaxial (bar $=7,5 \mathrm{~mm}$ ), D. Corte transversal do mesófilo foliar, visualizando a télia $($ bar $=139 \mu \mathrm{m})$ E. Corte transversal do mesófilo em detalhe para visualização da télia próximo a abertura do poro $(\mathrm{bar}=90 \mu \mathrm{m}) \mathbf{F}$. Estrutura telial contendo teliósporos $(\mathrm{bar}=73 \mu \mathrm{m})$, G. Teliósporos bicelulares maduros e imaturos $($ bar $=12 \mu \mathrm{m})$, H. Teliósporo em detalhe $(\mathrm{bar}=8 \mu \mathrm{m})$, I. Teliósporo bipapilar $(\mathrm{bar}=9 \mu \mathrm{m})$. 
A doença não foi detectada em outras hospedeiras; sendo restrita sua ocorrência em plantas do gênero Dichondra (MENDES; URBEN, 2016). Assim, plantas cultivadas pertencentes à mesma família botânica ou espécies congenéricas podem ser infectadas por estes fitopatógenos, sendo representadas em circunstâncias agrícolas como fonte de inóculo em lavouras.

\section{Conclusões}

Através da confluência ou similaridade da maioria das características morfológicas e morfométricas da ferrugem-da-orelha de rato oriunda de Bento Gonçalves, RS (2011) como sendo Puccinia dichondrae.

Este é o primeiro registro de ocorrência dessa doença em Bento Gonçalves - RS, Brasil.

\section{Referências Bibliográficas}

BEDENDO, I. P. Ferrugens. In BERGAMIM FILHO A.; KIMATI, H.; AMORIM, L. (Eds.) Manual de Fitopatologia. São Paulo-SP: Editora Agronômica Ceres, 2011, p. 231-287.

CARDIN, L.; DELECOLLE, B. ; MOURI, B. Occurrence of Alternaria dichondrae, Cercospora sp., and Puccinia sp. on Dichondra repens in France and Italy. Plant Disease, St. PaulUSA, v. 89, n. 9, p. 1012, 2005.

CUMMINS, G.E.; HIRATSUKA, Y. Illustrated Genera Rust Fungi. Revision Edition. St. Paul, Minnesota, USA: Minnesota Edition The American Phytopathology Society, 1983. p. 152.

DOIDGE, E.M. South African rust fungi. Part V. South Africa: Bothalia, 1948, p. 895-918.

EMMONS, R.; ROSSI, F. Turfgrass Science \& Management. $5^{\mathrm{a}}$ Ed. Stamford-USA: Cengage Learning, 2015,57 pp.
FARR, D. F.; ROSSMAN, A. Y. Fungal Databases, Systematic Botany and Mycology Laboratory. 2016. Disponível em: <http://nt.ars-grin.gov/fungaldatabases/>, Acesso em: 05 jan. 2016.

GAY, C. Historia fisica y politica de Chile segun documentos adquiridos en esta republica durante doce anos de residencia en ella y publicada bajo los auspicios del supremo gobierno. Paris, France: BHL Collections, 1852. (Botanica I. Tomo 8.)

HENNEN, J. F.; HENNEN, M. M.; FIGUEIREDO, M. B. Index of the rust fungi (Uredinales) of Brazil. Arch. Inst. Biol., supl. 1, v. 49, p. 1-201, 1982.

LORENZI, H. Plantas ornamentais no Brasil: arbustivas, herbáceas e trepadeiras. $3^{\text {a }}$ ed. Nova Odessa-SP: Instituto Plantarum, 2001, 1080 p.

LORENZI, H. Plantas daninhas do Brasil: terrestres, aquáticas, parasitas e tóxicas. $4^{\mathrm{a}}$ ed. Nova Odessa-SP: Instituto Plantarum, 2008, 640 p.

MENDES, M. A. S.; URBEN, A. F.; Fungos relatados em plantas no Brasil. Laboratório de Quarentena Vegetal. Brasília, DF: Embrapa Recursos Genéticos e Biotecnologia. $2016 . \quad$ Disponível em: <http://pragawall.cenargen.embrapa.br/aiqweb/michtml/micba nco01a.asp>. Acesso em: 01 set. 2016.

MUJICA, F.; VERGARA, C. Flora fungosa Chilena: Indice preliminar de los huespedes de los hongos chilenos y sus referencias bibliograficas. Imprenta Stanley, 1945, 199 p.

SACCARDO, P. A. Puccinia dichondrae. Sylloge Fungorum. v. VII, p. 717. 1888.

SARROCCO, S.; VERGARA, M.; VANNACCI, G. First confirmed report of the leaf rust Puccinia dichondrae on Dichondra repens in Italy. Plant Pathology, London-UK, v. 59, n. 4, p. 802, 2009. 